\title{
Analisis Ketahanan Bersekolah Anak Jenjang SMA/Sederajat di Provinsi DKI Jakarta Tahun 2019
}

\author{
Yaya Setiadi $^{1, \mathrm{a})}$, Alan Anugrah Tomanda ${ }^{2, \mathrm{~b})}$ \\ ${ }^{1}$ Politeknik Statistika STIS, Jl. Otista No. 64 C Jakarta Timur \\ ${ }^{2}$ Badan Pusat Statistik, Kab. Parigi Moutong, Bambalemo, Parigi, Sulawesi Tengah 94471 \\ E-mail: a)setiadi@stis.ac.id, b)alantomanda99@gmail.com
}

\begin{abstract}
The education is an important part of the progress of a nation, including Indonesia. The Ministry of Education and Culture's Strategic Plan which targets each level of education has a dropout rate of only 1 percent but the level of junior high school and high school has not reached the target in 2019. The 2019 Susenas shows that the highest school dropout rate occurs in DKI Jakarta which reached 6.13 percent even though DKI Jakarta was ranked second for the number of continuing education to high school/equivalent for the provinces in Java. In this study using Time to Event Analysis to find out how to describe the resilience of attending school at a high school level/equivalent and the factors that influence. So based on the lowest Akaike Information Criterion (AIC) value, the Gompertz distribution parametric model was chosen. Based on the results of the study it is known that there is one independent variable that affects the resilience of attending high school/equivalent in 2019, namely the working status of children in which children who are working have a 4.44 times greater risk than children who are not working. This research is important because DKI Jakarta has a literacy rate of 99.74 percent and the ratio of student teachers to the ideal standard but has the highest dropout rate in Indonesia and the Nett Enrollment Ratio (NER) is always below the national average in 5 years (2015-2019).
\end{abstract}

Keywords: school endurance, time to event analysis, gompretz

\begin{abstract}
Abstrak
Pendidikan menjadi salah satu bagian yang penting dalam kemajuan suatu bangsa termasuk Indonesia. Rencana Strategis Kementerian Pendidikan dan Kebudayaan yang menargetkan setiap jenjang pendidikan memiliki angka putus sekolah hanya 1 persen tetapi jenjang SMP/sederajat dan SMA sederajat belum mencapai target tersebut di tahun 2019. Data Susenas 2019 menunjukkan bahwa secara Nasional angka putus sekolah tertinggi tingkat SMA/sederajat terjadi di DKI Jakarta yang mencapai 6,13 persen walaupun DKI Jakarta berada diperingkat kedua untuk angka melanjutkan pendidikan ke SMA/sederajat untuk provinsi yang ada di Pulau Jawa. Penelitian ini menggunakan Time to Event Analysis untuk mengetahui bagaimana gambaran ketahanan bersekolah pada jenjang SMA/sederajat dan faktor-faktor yang memengaruhinya. Berdasarkan nilai Akaike Information Criterion (AIC) terendah maka dipilih model parametrik distribusi Gompertz. Hasil analisis data diperoleh kesimpulan bahwa terdapat satu variabel bebas yang memengaruhi ketahanan bersekolah jenjang SMA/sederajat di Provinsi DKI Jakarta tahun 2019 yaitu status bekerja anak, dimana anak yang berstatus bekerja memiliki resiko 4,44 kali lebih besar untuk putus sekolah dibandingkan anak yang tidak bekerja. Penelitian ini penting dilakukan karena DKI Jakarta memiliki angka melek huruf yang mencapai 99,74 persen dan rasio guru murid yang sesuai standar ideal
\end{abstract}


namun memiliki angka putus sekolah tertinggi di Indonesa dan Angka Partisipasi Murni (APM) yang selalu di bawah rata-rata Nasional dala 5 tahun terakhir (2015-2019).

Kata-kata kunci: ketahanan bersekolah, time to event analysis, gompertz

\section{PENDAHULUAN}

Pendidikan mempunyai peran utama dalam menyiapkan sumber daya manusia yang berkualitas dan merupakan syarat dalam mewujudkan pembangunan berkelanjutan. Sesuai dengan fungsi dan tujuan pendidikan nasional dalam UU No. 20 Tahun 2003 yaitu untuk mengembangkan kemampuan dan membentuk watak serta peradaban bangsa yang bermartabat sehingga dapat mencapai tujuan yaitu untuk berkembangnya potensi peserta didik agar menjadi manusia yang beriman dan bertakwa kepada Tuhan Yang Maha Esa, berakhlak mulia, sehat, berilmu, cakap, kreatif, mandiri, dan menjadi warga negara yang demokratis serta bertanggung jawab. Semakin tinggi tingkat pendidikan suatu negara mengindikasikan keadaan tingkat kemajuan dari bangsa tersebut karena dapat dilihat dari sarana dan prasarana pendidikan yang dimiliki yang bergantung juga pada kebijakan di bidang pendidikan yang tepat dan terlaksana dengan baik. Di Indonesia telah dirancangkan suatu program peningkatan kualitas pendidikan dengan adanya program Indonesia pintar yang tercantum pada Rencana Pembangunan Jangka Menengah (RPJMN) 2015-2019 bahkan juga terdapat Nawacita tujuan yang kelima "Meningkatkan kualitas hidup manusia Indonesia melalui peningkatan pendidikan dan pelatihan dengan Program Indonesia Pintar". Sasaran yang ingin dicapai dalam Program Indonesia Pintar melalui pelaksanaan Wajib Belajar 12 Tahun pada RPJMN 2105-2019 adalah meningkatkan angka keberlanjutan pendidikan yang dapat diidentifikasi melalui persentase angka putus sekolah yang menurun. Demikian halnya pada Rencana Strategis (Renstra) Kementerian Pendidikan dan Kebudayaan yang menargetkan untuk setiap jenjang pendidikan memiliki angka putus sekolah hanya sebesar satu persen (Renstra 2015-2019 Kementerian Pendidikan dan Kebudayaan, 2015). Untuk jenjang pendidikan SD/sederajat sudah mencapai target dari Renstra Kemendikbud. Namun untuk jenjang SMP/sederajat maupun jenjang SMA/sederajat masih belum mencapai target dimana angka putus sekolahnya sebesar 1,67 persen untuk SMP/sederajat dan 2,94 persen untuk jenjang SMA/sederajat (Renstra 2015-2019 Kementerian Pendidikan dan Kebudayaan, 2015).

Angka putus sekolah di Indonesia berdasarkan data BPS dalam "Potret Pendidikan Indonesia Statistik Pendidikan 2019" menunjukan Provinsi DKI Jakarta sebagai provinsi yang memiliki angka putus sekolah tertinggi se-Indonesia untuk tingkat SMA/sederajat. Selain itu di Provinsi DKI Jakarta semakin tinggi tingkat pendidikan semakin tinggi angka putus sekolahnya. Pada tingkat SD/sederajat angka putus sekolahnya sebesar 0,09 persen, SMP/sederajat sebesar 0,21 persen dan pada tingkat SMA/sederajat sebesar 6,13 persen. Gambaran kondisi pendidikan Provinsi DKI Jakarta yang dilihat berdasarkan Angka Partisipasi Murni yang dalam lima tahun terakhir terus mengalami peningkatan namun selalu berada di bawah rata-rata nasional menunjukan pelaksanaan pendidikan yang masih kurang baik. Sedangkan rasio murid terhadap guru untuk SMA/sederajat di Provinsi DKI Jakarta adalah 15 yang menunjukan rasio yang sudah ideal karena berada di bawah rasio standar yaitu 20. Selain itu angka melek huruf usia 15 tahun ke atas juga berada di atas rata-rata nasional yaitu sebesar 99,74 persen. Provinsi DKI Jakarta berada di peringkat kedua teratas untuk angka melanjutkan pendidikan ke SMA/sederajat untuk provinsi yang ada di Pulau Jawa. Namun angka putus sekolah Provinsi DKI Jakarta sebesar 6,13 yang jauh diatas angka putus sekolah nasional yaitu 1,76 dan meningkatnya angka putus sekolah yang terjadi seiring bertambahnya jenjang pendidikan. Oleh karena itu, fokus penelitian ini ditujukan pada Provinsi DKI Jakarta untuk jenjang pendidikan SMA/sederajat.

Penelitian sebelumnya tentang anak putus sekolah (Sugianto, 2017) di Kecamatan Batang Cenaku Kabupaten Inderagiri Hulur masalah utamanya pada faktor ekonomi dan tingkat pendidikan orang tua. Hasil penelitian Choiriyah (2009) di Surabaya Utara yang memengaruhi tinggi angka putus sekolah salah satunya adalah aspek demografi (jenis kelamin anak). Selain itu penelitian lain juga menemukan bahwa anak yang bekerja untuk memenuhi kebutuhan ekonomi menyebabkan terjadinya putus sekolah (Utami dan Febri, 2019).

Penelitian ini bertujuan untuk mengetahui gambaran karakteristik penduduk putus sekolah, gambaran ketahanan bersekolah dan faktor-faktor yang memengaruhi ketahanan bersekolah untuk 
tingkat SMA/sederajat di Provinsi DKI Jakarta tahun 2019. Penelitian ini menggunakan lima variabel bebas yang diduga memengaruhi ketahanan bersekolah anak yaitu jenis kelamin anak, pendidikan kepala rumah tangga, status bekerja anak, jumlah anggota rumah tangga dan status orang tua (Sugianto, 2017).

\section{METODOLOGI}

Menurut Undang-Undang No. 20 Tahun 2003, pendidikan adalah usaha sadar dan terencana untuk mewujudkan suasana belajar dan proses pembelajaran agar peserta didik secara aktif mengembangkan potensi dirinya untuk memiliki kekuatan spiritual keagamaan, pengendalian diri, kepribadian, kecerdasan, akhlak mulia, serta keterampilan yang diperlukan dirinya, masyarakat, bangsa dan negara (pasal 1 ayat 1). Menurut Ary H. Gunawan (2010) putus sekolah adalah predikat yang diberikan kepada mantan peserta didik yang tidak mampu menyelesaikan suatu jenjang pendidikan, sehingga tidak dapat melanjutkan studinya ke jenjang pendidikan berikutnya.

\section{Bahan dan Data}

Penelitian ini mencakup wilayah Provinsi DKI Jakarta pada tahun 2019. Pada penelitian ini menggunakan raw data Survei Sosial Ekonomi Nasional (Susenas) KOR Maret tahun 2019 yang diperoleh dari Badan Pusat Statistik (BPS). Dalam penelitian ini kategori anak putus sekolah yang digunakan adalah anak yang tidak bersekolah lagi dan sebelumnya pernah mengikuti pendidikan di SMA/sederajat tetapi tidak lulus SMA/sederajat dengan ijazah tertinggi yang dimiliki adalah tingkat SMP/sederajat yang termasuk dalam sampel Survei Sosial Ekonomi Nasional (Susenas) KOR Maret tahun 2019 di Provinsi DKI Jakarta. Susenas 2019 dilaksanakan di seluruh provinsi di Indonesia dengan ukuran sampel 320.000 rumah tangga yang tersebar di 514 kabupaten/kota di Indonesia. Sampel tidak termasuk rumah tangga yang tinggal dalam blok sensus khusus dan rumah tangga khusus seperti asrama, penjara, dan sejenisnya tetapi rumah tangga yang berada di blok sensus biasa dan penarikan sampel dilakukan dengan metode two stages one phase stratified sampling secara probability. Anak yang masuk dalam kategori putus sekolah sebelum akhir periode penelitian dikategorikan sebagai event sedangkan untuk anak yang telah lulus SLTA/sederajat atau yang masih bersekolah hingga akhir periode penelitian dikategorikan sebagai censor.

\section{Metode Penelitian}

Penelitian ini menggunakan dua metode analisis yaitu metode analisis deskriptif dan analisis inferensia. Analisis deskriptif bertujuan untuk memberikan gambaran mengenai suatu data agar lebih mudah dipahami, yakni menggunakan grafik serta kurva Kaplan-Meier yang bertujuan untuk mengetahui gambaran ketahanan bersekolah. Sedangkan analisis inferensia menggunakan analisis ketahanan hidup (Time to Event analysis / Survival Analysis) untuk mengetahui faktor-faktor yang memengaruhi ketahanan bersekolah.

\section{Time to Event Analysis}

Metode ini merupakan metode statistik yang digunakan untuk menganalisis variabel yang menyatakan durasi waktu sampai terjadinya suatu peristiwa tertentu (Kleinbaum \& Klein, 2005). Terdapat tiga unsur penting dalam analisis ini yaitu waktu, event (kejadian/kegagalan) dan juga censor.

Time to event analysis dilakukan dengan beberapa tahapan sebagai berikut.

1. Pengujian Asumsi Proportional Hazard (PH)

Pengujian asumsi PH menggunakan Goodness of Fit Test (GoF). GoF dilakukan menggunakan Schoenfeld Residual dari semua variabel bebas yang digunakan pada model untuk setiap objek penelitian yang mengalami kejadian (event).

2. Pemilihan Model Terbaik

Akaike Information Criterion (AIC) digunakan untuk menentukan model terbaik, yaitu model yang paling sederhana namum dapat menggambarkan keragaman ketahanan hidup sebanyak mungkin. Model terbaik adalah model dengan nilai AIC terkecil. 
3. Pembentukan Model

Setelah diperoleh nilai AIC terkecil, maka dilakukan pemodelan pada semua variabel bebas yang memenuhi asumsi proportional hazard untuk mendapatkan model terbaik. Model cox proportional hazard dapat dituliskan sebagai berikut:

$$
h(t, X)=h_{0}(t) \cdot \exp \left(\sum_{i}^{p} \beta_{i} X_{i}\right)
$$

4. Pengujian Parameter

a. Pengujian parameter secara simultan

Hipotesis :

$\mathrm{H}_{0}: \beta 1=\beta 2=\ldots=\beta 5=0$

(tidak terdapat variabel bebas yang memengaruhi variabel terikat)

$\mathrm{H}_{1} \quad: \beta i \neq 0$

(minimal ada variabel bebas yang memengaruhi variabel terikat)

keterangan : $i=1,2, \ldots, 5$

Tolak $\mathrm{H}_{0}$ jika atau $p$-value $<\alpha$. Menunjukkan bahwa miminal terdapat satu variabel bebas yang memengaruhi variabel terikat sehingga selanjutnya dilakukan pengujian secara parsial pada masing-masing variabel bebas.

b. Pengujian parameter secara parsial.

Hipotesis :

$\mathrm{H}_{0} \quad: \beta i=0$ (variabel bebas ke-j tidak berpengaruh terhadap variabel terikat)

$\mathrm{H}_{1} \quad: \beta i \neq 0$ (variabel bebas ke-j berpengaruh terhadap variabel terikat)

keterangan : $j=1,2, \ldots, 5$

Tolak $\mathrm{H}_{0}$ jika $x^{2}>x^{2}{ }_{(p, a)}$ atau $p-$ value $<\alpha$. Menunjukkan bahwa variabel bebas tersebut memengaruhi variabel terikat.

\section{HASIL DAN PEMBAHASAN}

\section{Gambaran Umum Data}

Dalam penelitian ini yang masuk ke dalam unit analisis adalah anak yang memiliki ijazah tertingi pada jenjang SMP/sederajat dan sudah melanjutkan pendidikan pada jenjang SMA/sederajat. Berdasarkan hasil Susenas tahun 2019 di Provinsi DKI Jakarta terdapat 716 orang yang tercakup dalam penelitian ini yang terdiri dari 646 anak (90,2 persen) yang status pendidikannya masih besekolah (censor) dan terdapat 70 anak (9,8 persen) yang sudah berhenti sekolah atau tidak sekolah lagi (event). Pada GAMBAR 1 dapat diketahui persentase anak putus sekolah berdasarkan kategori pada masingmasing variabel bebas yang digunakan dibandingkan dengan jumlah sampel pada masing-masing kategori.

GAMBAR 1 menunjukan kejadian putus sekolah pada setiap variabel bebas yang digunakan, berdasarkan kategori banyak terjadi pada anak dengan jenis kelamin laki-laki (11,1 persen), memiliki kepala rumah tangga dengan tingkat pendidikan kurang dari SMA (13,4 persen), anak dengan status bekerja (54,1 persen), jumlah anggota keluarga kurang dari sama dengan empat ( 9,9 persen) dan anak dengan orang tua tunggal $(15,1$ persen$)$. 


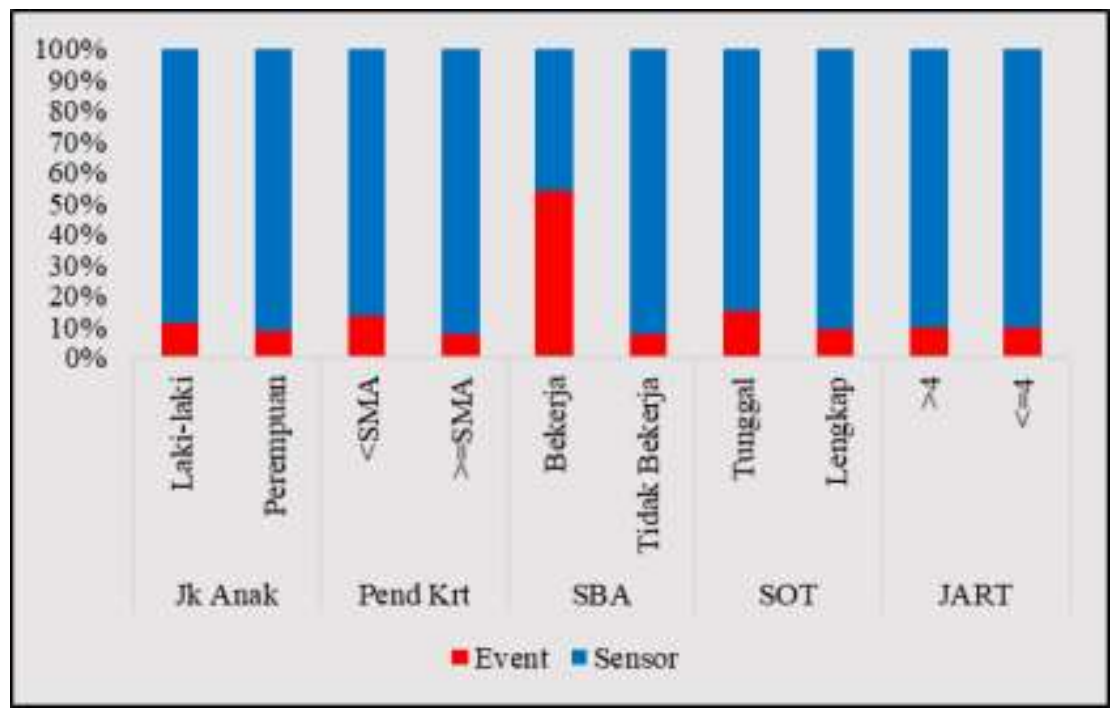

GAMBAR 1. Grafik presentase kejadian putus sekolah pada masing-masing kategori setiap variabel bebas

\section{Gambaran Ketahanan Bersekolah}

Untuk menggambarkan ketahanan bersekolah anak pada jenjang SMA/sederajat di Provinsi DKI Jakarta tahun 2019 digunakan kurva Kaplan-Meier pada masing-masing variabel bebas. Kemudian dilakukan uji log-rank untuk mengetahui apakah terjadi perbedaan yang signifikan pada kategorikategori setiap variabel bebas, hasil uji log-rank dapat dilihat pada TABEL 1.

\section{Jenis Kelamin}

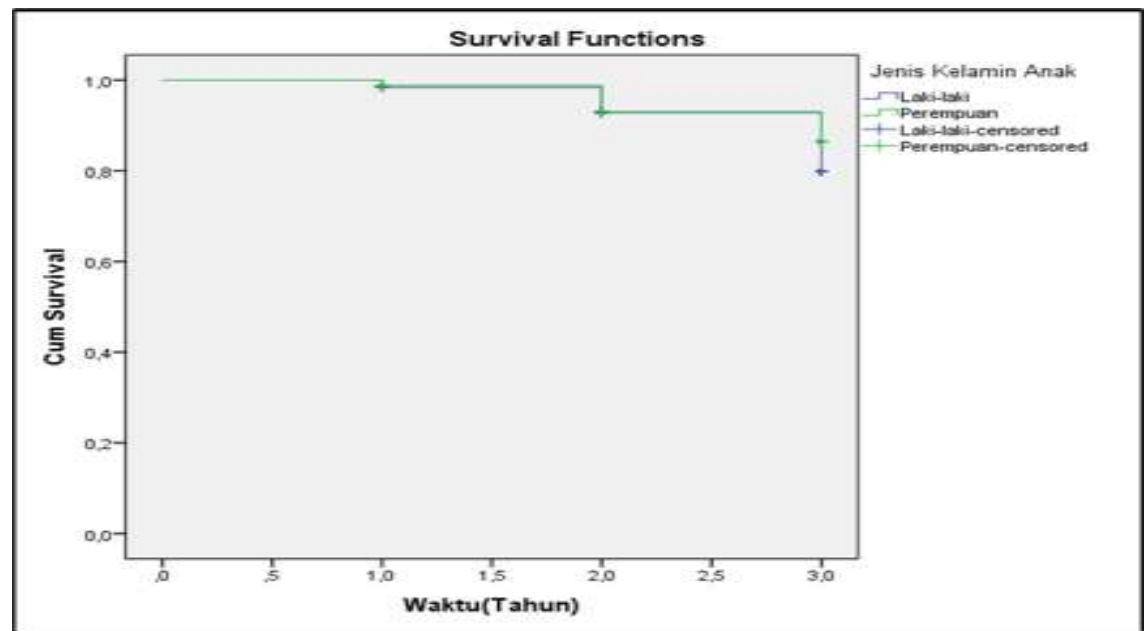

GAMBAR 2. Kurva ketahanan bersekolah pada jenjang SMA/sederajat menurut jenis kelamin

Pada GAMBAR 2 dapat dilihat jarak antara kurva laki-laki dan kurva perempuan yang berhimpit dan jarak yang sangat kecil yang menunjukan tidak adanya perbedaan ketahanan sekolah yang signifikan antara kedua kategori tersebut. Hal ini didukung oleh hasil uji log rank yang tidak signifikan yang dilihat dari hasil $p$-value $=0,215>\alpha=0,05$. 
Pendidikan Kepala Rumah Tangga (KRT)

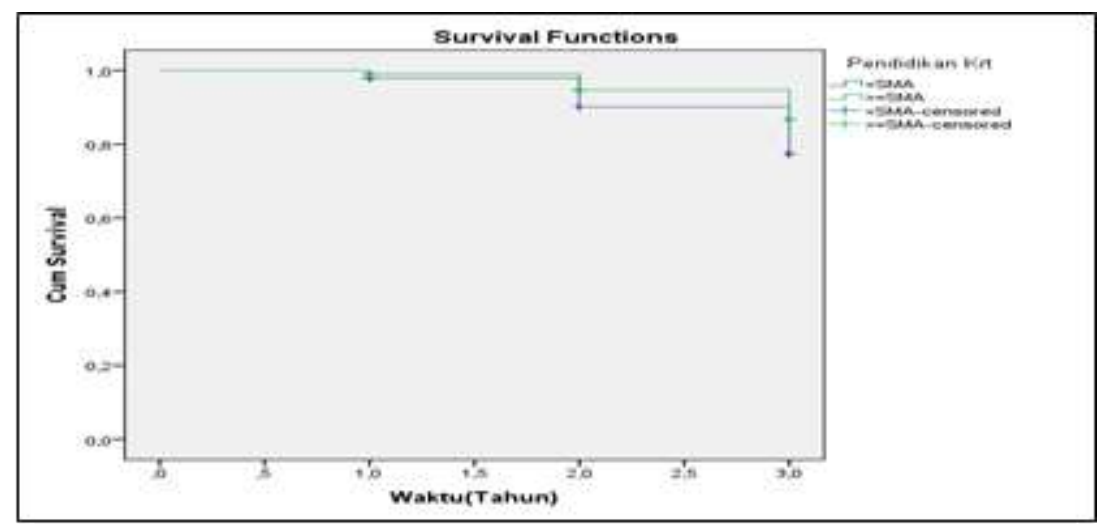

GAMBAR 3. Kurva ketahanan bersekolah anak pada jenjang SMA/sederajat menurut pendidikan kepala rumah tangga

Berdasarkan GAMBAR 3 terlihat bahwa kurva pendidikan KRT kurang dari SMA dan kurva pendidikan KRT SMA ke atas terdapat jarak sehingga dapat dikatakan memiliki perbedaan ketahanan, hal ini didukung oleh hasil uji log rank yang signifikan dibuktikan dari hasil $p$-value $=0,010<$ $\alpha=0,05$. Kurva pendidikan KRT kurang dari SMA berada di bawah sehingga diketahui bahwa ketahanan bersekolah anak dengan pendidikan KRT SMA ke atas lebih baik dari pada ketahanan bersekolah anak dengan pendidikan KRT kurang dari SMA.

Status Bekerja Anak

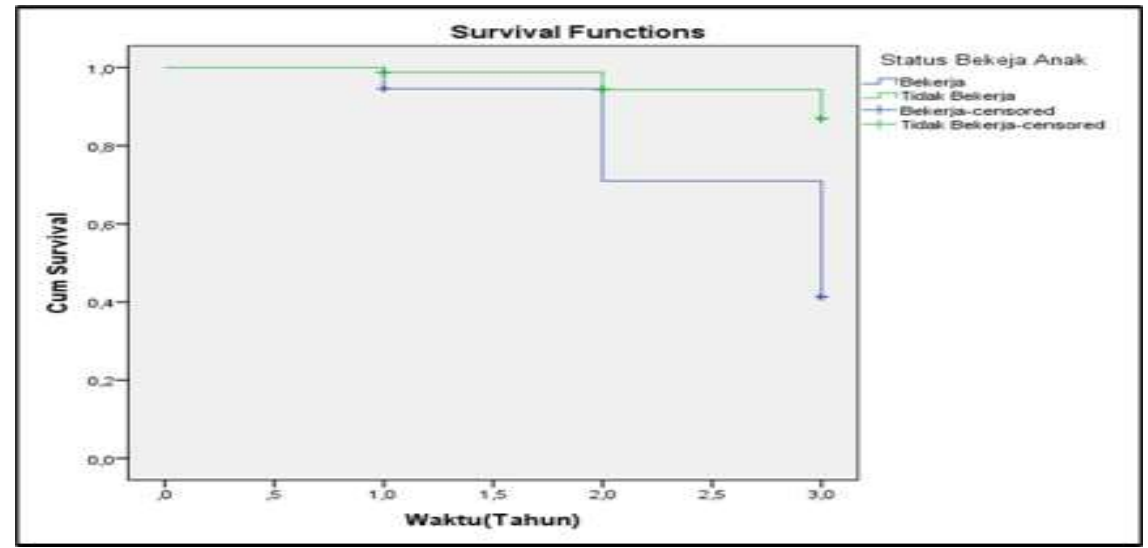

GAMBAR 4. Kurva ketahanan bersekolah anak pada jenjang SMA/sederajat menurut status bekerja anak

Perbandingan ketahanan bersekolah berdasarkan status bekerja anak dapat dilihat pada GAMBAR 4. Terdapat jarak antara kurva bekerja dan kurva tidak bekerja yang berarti terdapat perbedaan antara kedua kategori tersebut. Hal ini didukung oleh hasil uji log rank yang signifikan dibuktikan dengan hasil $p$-value $=0,00<\alpha=0,05$. Dapat dilihat bahwa posisi kurva tidak bekerja berada di atas kurva bekerja, hal ini berarti bahwa ketahanan sekolah anak dengan status tidak bekerja lebih baik dari pada anak dengan status bekerja. 
Jumlah ART

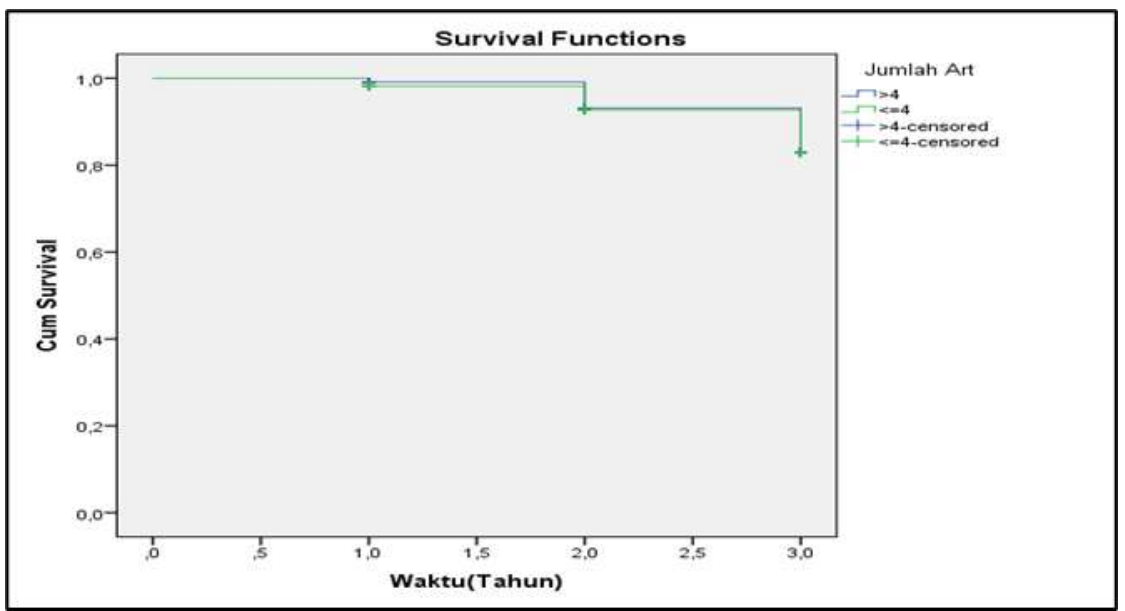

GAMBAR 5. Kurva ketahanan bersekolah pada jenjang SMA/sederajat menurut jumlah anggota rumah tangga

GAMBAR 5 menunjukan jarak kurva yang cenderung berhimpit menunjukan perbedaan yang kecil ketahanan anak bersekolah antara anak dengan jumlah anggota rumah tangga lebih kecil sama dengan empat orang dan anak dengan jumlah anggota rumah tangga lebih dari empat orang. Hasil uji log rank diketahui bahwa perbedaan antara kedua kategori tersebut tidak signifikan dengan melihat $p-$ value $=$ $0,811>\alpha=0.05$.

\section{Status Orang Tua}

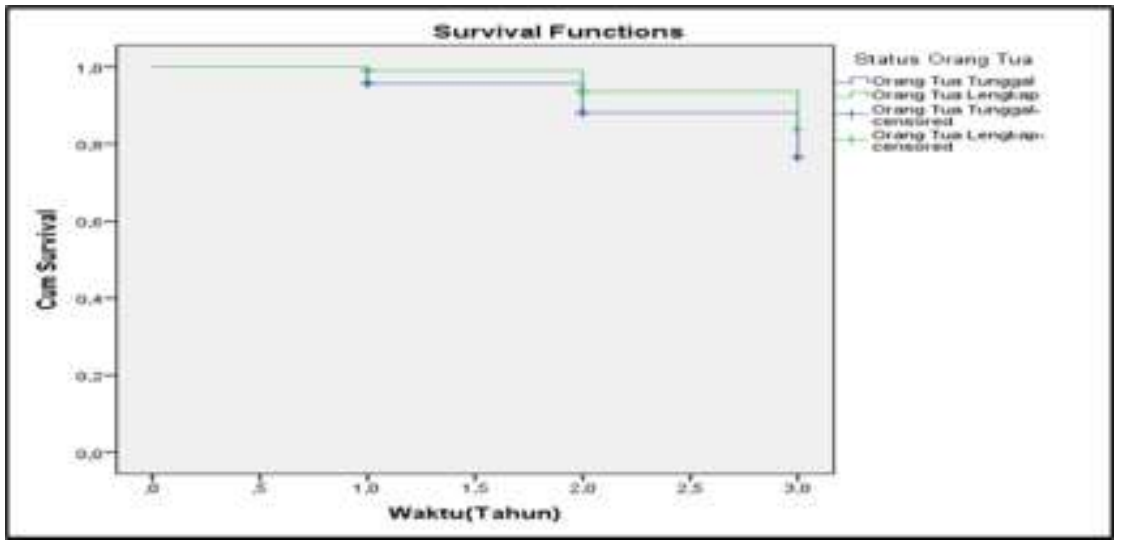

GAMBAR 6. Kurva ketahanan bersekolah pada jenjang SMA/sederajat menurut status orang tua

Dari GAMBAR 6 terlihat adanya jarak pada antara kurva orang tua tunggal dan kurva orang tua lengkap yang menunjukan terdapat perbedaan antara kedua kategori tersebut. Namun perbedaan tersebut tidak signifikan sehingga tidak dapat dikatakan bahwa ketahanan bersekolah anak dengan status orang tua tunggal lebih kecil dibandingkan ketahanan bersekolah anak dengan status orang tua lengkap ataupun sebaliknya. Hal ini dapat ditunjukan oleh hasil uji log rank pada TABEL 1 yang menunjukan perbedaan yang tidak signifikan berdasarkan nilai $p-$ value $=0,068>\alpha=0,05$. 
TABEL 1. Hasil Uji Log Rank

\begin{tabular}{cc}
\hline Variabel & $\boldsymbol{P}$-Value \\
\hline Jenis Kelamin Anak & 0,215 \\
Pendidikan KRT & 0,010 \\
Status Bekerja Anak & 0,000 \\
Jumlah ART & 0,811 \\
Status Orang Tua & 0,068 \\
\hline Sumber: Susenas 2019, Data diolah
\end{tabular}

\section{Ketahanan Bersekolah berdasarkan Variabel yang memengaruhi}

Penentuan Asumsi PH

Pada penelitian ini perlu dilakukan pengujian asumsi proportional hazard yang mana hazard ratio tidak bergantung pada waktu $t$ sehingga akan konstan dari waktu ke waktu. Salah satu cara untuk melihat terpenuhinya asumsi PH dapat dilakukan menggunakan residual Schoenfeld test, dimana asumsi PH akan terpenuhi apabila p-value yang dihasilkan $>\alpha(0,05)$. Pada TABEL 2 dapat dilihat bahwa semua variabel bebas yang digunakan memenuhi asumsi $\mathrm{PH}$.

TABEL 2. Hasil Residual Schoenfeld test

\begin{tabular}{cc}
\hline Variabel & $\boldsymbol{P}$-Value \\
\hline Jenis Kelamin Anak & 0,4246 \\
Pendidikan KRT & 0,7273 \\
Status Bekerja Anak & 0,8320 \\
Jumlah ART & 0,8520 \\
Status Orang Tua & 0,2144 \\
\hline Sumber: Susenas 2019, Data diolah
\end{tabular}

Pemilihan Model Terbaik

Setelah semua variabel bebas diketahui memenuhi asumsi proportional hazard maka selanjutnya adalah mencari model distribusi yang paling sesuai dari distribusi parametrik (eksponensial, weibull dan gompertz) maupun distribusi semi parametrik (cox proportional hazard). Penentuan distribusi yang paling sesuai dilakukan dengan menggunakan nilai AIC, semakin rendah nilainya maka semakin tinggi kecocokan nilainya. Nilai AIC untuk masing-masing distribusi dapat dilihat pada TABEL 3. Berdasarkan nilai AIC diketahui bahwa distribusi Gompertz memiliki nilai AIC yang paling rendah yaitu sebesar 327,5576 sehingga untuk mengindentifikasi faktor-faktor yang memengaruhi ketahanan bersekolah jenjang SMA/sederajat di Provinsi DKI Jakarta tahun 2019 menggunakan model Proportional Hazard Gompertz yang bersifat parametrik.

TABEL 3. Akaike Information Criterion

\begin{tabular}{cc}
\hline Model & AIC \\
\hline Gompretz & 327,5576 \\
Weibull & 331,5359 \\
Eksponential & 437,7257 \\
Cox PH & 821,364 \\
\hline \multicolumn{2}{l}{ Sumber: Susenas 2019, Data diolah }
\end{tabular}

\section{Pembentukan Model Ketahanan Bersekolah}

Semua variabel bebas yang memenuhi asumsi proportional hazard kemudian dilakukan pemodelan model parametrik dengan distribusi Gompertz yang hasilnya dapat dilihat pada TABEL 4. Di bawah ini. Selain itu, didapatkan hasil uji simultan yang signifikan berdasarkan nilai likelihood ratio test 
sebesar 29,12 dengan $p$-value sebesar 0,000 yang kurang dari nilai $\alpha$ sebesar 0,05 . Sehingga diketahui bahwa dengan tingkat signifikasi 0,05 terdapat cukup bukti bahwa minimal satu variabel bebas yang memengaruhi variabel terikat.

TABEL 4. Pemodelan Model Parametrik dengan Distribusi Gompertz,

\begin{tabular}{|c|c|c|c|c|}
\hline Variabel & Kategori & $\beta$ & Hazard Radio & P-Value \\
\hline \multirow{2}{*}{ Jenis Kelamin } & Laki-laki (ref) & & & \\
\hline & Perempuan & $-0,0400413$ & 0,9607497 & 0,873 \\
\hline \multirow{2}{*}{ Pendidikan KRT } & $>=$ SMA (ref) & & & \\
\hline & $<$ SMA & 0,2200722 & 1,246167 & 0,390 \\
\hline \multirow{2}{*}{$\begin{array}{l}\text { Status Bekerja } \\
\text { Anak }\end{array}$} & $\begin{array}{l}\text { Tidak Bekerja } \\
\text { (ref) }\end{array}$ & & & \\
\hline & Bekerja & 1,490608 & 4,439794 & $0,000 *$ \\
\hline \multirow{2}{*}{ Jumlah Art } & $<=4$ (ref) & & & \\
\hline & $>4$ & $-0,2113614$ & 0,8094815 & 0,397 \\
\hline \multirow{2}{*}{ Status Orang Tua } & Lengkap (ref) & & & \\
\hline & Tunggal & 0,2868845 & 1,33227 & 0,346 \\
\hline Intercept $\left(\beta_{0}\right)$ & & $-8,184589$ & & \\
\hline gamma & & 1,670143 & & \\
\hline
\end{tabular}

Berdasarkan TABEL 4. model yang terbentuk dari distribusi Gompertz yang merupakan model parametrik dari semua variabel bebas yang memenuhi asumsi PH dan juga dari hasi uji simultan maka dapat dilihat bahwa terdapat satu variabel yang signifikan yaitu status bekerja anak.

$$
\begin{aligned}
& \hat{h}(t, x)=\exp (1,670143 t) \exp (-8,184589+0,0400413 \text { Jenis Kelamin } \\
& \quad+0,2200722 \text { Pendidikan KRT }+1,490608 \text { Status Bekerja Anak } \\
& \quad-0,2113614 \text { Jumlah Art }+0,2868845 \text { Status Orang Tua })
\end{aligned}
$$

Ket $: *=$ signifikasi pada $\alpha(0,05)$

\section{Analisis Hasil}

Baseline Hazard

Nilai baseline hazard memiliki bentuk $\widehat{h_{0}}(t)=\exp (\hat{\gamma} t)$ yang pada penelitian ini digunakan nilai/gamma sebagai penduga dari $\gamma$. Pada model terbaik yang terbentuk diketahui bahwa nilai/gamma adalah 1,670143 maka baseline hazard berbentuk $\widehat{h_{0}}(t)=\exp (1,67 t)$. Nilai ini menunjukan bahwa resiko terjadinya putus sekolah pada jenjang SMA/sederajat di Provinsi DKI Jakarta tahun 2019 meningkat seiring bertambahnya waktu.

\section{Status Bekerja Anak}

Penelitian ini menggunakan status anak tidak bekerja sebagai kategori referensi untuk variabel status bekerja anak. Variabel ini berpengaruh secara signifkan baik simultan maupun parsial dengan $p-$ value $<\alpha(0,05)$. Diketahui nilai $\beta$ sebesar 1,49 yang bertanda positif menunjukan bahwa anak yang memiliki status bekerja lebih beresiko untuk putus sekolah dari pada anak yang tidak bekerja. Hal ini ditunjukan dengan nilai hazard ratio sebesar 4,44 yang berarti bahwa anak pada jenjang SMA/sederajat yang bekerja memiliki resiko untuk putus sekolah 4,44 kali dibandingkan anak pada jenjang SMA/sederajat yang tidak bekerja. 
Hal ini sejalan dengan Hastadewi (2004), Utami dan Febri (2019) yang mana ketika anak melakukan dua kegiatan yaitu, bersekolah dan juga bekerja maka ia diharuskan memiliki kondisi fisik yang lebih kuat (terdapat beban ganda) dan dapat membagi waktu antara bekerja dan sekolah sehingga jika tidak dapat diatasi maka anak terpaksa putus sekolah di tengah jalan. Selain itu anak yang bekerja juga meningkatkan peluang anak untuk berhenti sekolah seperti yang dikemukakan oleh Rumberger (2001) dan Sabates dkk. (2010). Menurut Sahu (2013), Utami dan Febri (2019) kegiatan bekerja ini dapat dilatarbelakangi oleh kondisi ekonomi yang kurang tercukupi atau pendapatan rumah tangga yang rendah sehingga terjadi tuntutan ekonomi yang mengharuskan anak untuk bekerja.

\section{KESIMPULAN DAN SARAN}

\section{Kesimpulan}

Perbedaan ketahanan bersekolah anak pada jenjang SMA/sederajat di Provinsi DKI Jakarta tahun 2019 terjadi pada tingkat pendidikan kepala rumah tangga dan status bekerja anak. Ketahanan bersekolah anak dengan pendidikan kepala rumah tangga SMA ke atas lebih baik dari pada anak dengan pendidikan kepala rumah tangga kurang dari SMA. Ketahanan bersekolah anak yang berstatus tidak bekerja lebih baik dibandingkan anak yang berstatus bekerja. Dalam penelitian ini terdapat satu variabel yang memiliki pengaruh yang signifikan terhadap ketahanan bersekolah anak pada jenjang SMA/sederajat di Provinsi DKI Jakarta tahun 2019 yaitu status bekerja anak.

\section{Saran}

Untuk penelitian selanjutnya dapat menggunakan data primer untuk mendapatkan variabel tambahan seperti motivasi belajar anak, dan waktu tempuh anak dari rumah ke sekolah.

\section{UCAPAN TERIMA KASIH}

Terima kasih penulis ucapkan kepada Direktur Politeknik Statistika STIS beserta jajarannya yang telah mendukung penelitian ini sampai selesai.

\section{REFERENSI}

Badan Pusat Statistik. (2019). Survei Sosial Ekonomi Nasional 2019 Maret (KOR). Jakarta : Badan Pusat Statistik. Diakses pada tanggal 30 April 2020 melalui https://silastik.bps.go.id/v3/index.php/mikrodata/view/Wk1MeXd3OFpHOVIwZOFVOEprYTFVZ z09.

Badan Pusat Statistik. (2019). Potret Pendidikan Indonesia Statistik Pendidikan Tahun 2019. Jakarta : Badan Pusat Statistik.

Badan Pusat Statistik. (2019). Statistik Kesejahteraan Rakyat Provinsi di Jakarta 2019. Jakarta : Badan Pusat Statistik.

Choiriyah NI. (2009). Karakteristik Siswa Putus Sekolah Tingkat SD dan SMP di Kawasan Surabaya Utara [Skripsi]. Surabaya : Institut Teknologi Sepuluh November.

Gunawan, Ary H. (2010). Sosiologi Pendidikan Suatu Analisis Sosiologi tentang Pelbagai Problem Pendidikan. Jakarta : Rineka Cipta.

Hastadewi, Yuli. (2004). Kondisi dan Situasi PEKERJA ANAK pada Beberapa Sektor di Tulung agung dan Probolinggo, Jawa Timur. Citra Grafika : Jakarta

Kementerian Pendidikan dan Kebudayaan. (2015). Rencana Strategis Kementerian Pendidikan dan Kebudayaan Tahun 2015-2019. Jakarta : Kementerian Pendidikan dan Kebudayaan.

Kementerian Pendidikan dan Kebudayaan. Sistem Informasi Manajeman Keuangan. Jakarta : Kementerian Pendidikan dan Kebudayaan. Diakses pada tanggal 17 Maret 2020 melalui 
http://simkeu.kemdikbud.go.id/index.php/peraturan1/8-uu-undang-undang/12-uu-no-20-tahun2003-tentang-sistem-pendidikan-nasional.

Kleinbaum, D. G. dan Klein, M. (2005). Survival Analysis A Self-Learning Text. New York : Springer Science Business Media, Inc.

Lee, E. T. dan Wang, J. W. (2003). Statsitical Methods for Survival Data Analysis. Canada : JohnWiley $\&$ Sons, Inc

Rumberger, W. Russel. (2001). Why Students Drop Out and What Can Be Done. 30 Januari 2020. https://www.researchgate.net/publication/267552507

Sabates, R.,A.Hossain, K.M.Lewin.(2010). School Drop Out in Bangladesh: New Insight From Longitudinal Evidence. Sussex: Create.

Sahu Kabita Kumari, “An Emperical Study of Determinants of ChildLabour”, International Journal of Science, Environment andTechnology ISSN 2278-3687(O), Vol. 2, No 3, 2013, 423-433

Sugianto, E. (2017). Faktor Penyebab Anak Putus Sekolah Tingkat SMA Di Desa Bukit Lipai Kecamatan Batang Cenaku Kabupaten Inderagiri Hulu. Jurnal Sosiologi Fakultas Ilmu Sosial dan Ilmu Politik Universitas Riau, Vol.4, No.2, - Oktober 2017.

Utami, E.T \& Febri,W. (2019). Determinan Partisipasi Sekolah Di Indonesia Analisis Data Susenas Tahun 2017. Jurnal Ilmiah WIDYA Non-Eksakta. Vol. 1, No. 1 (2019). 